Article

\title{
Effect of Cold Rolling and Heat Treatment on the Mechanical Properties of GH4169 Alloy Sheet at Room Temperature
}

\author{
Shi-Hong Zhang ${ }^{1,+}$, Neng-Yong Ye ${ }^{1,2,+}$, Ming Cheng ${ }^{1,2, *}$, Hong-Wu Song ${ }^{1}$, Hong-Wei Zhou ${ }^{2}$ \\ and Ping-Bo Wang ${ }^{2}$
}

Received: 31 October 2015; Accepted: 15 December 2015; Published: 23 December 2015

Academic Editor: Johan Moverare

1 Institute of Metal Research, Chinese Academy of Sciences, Shenyang 110016, China; shzhang@imr.ac.cn (S.-H.Z.); nyye12b@imr.ac.cn (N.-Y.Y.); hwsong@imr.ac.cn (H.-W.S.)

2 State Key Laboratory of Advanced Processing and Recycling of Non-ferrous Metals, Lanzhou University of Technology, Lanzhou 730050, China; zhouhongwei126ct@126.com (H.-W.Z.); wpb_lut@126.com (P.-B.W.)

* Correspondence: mcheng@imr.ac.cn; Tel.: +86-24-8397-0196; Fax: +86-24-2389-1320

+ These authors contributed equally to this work.

\begin{abstract}
The mechanical properties of GH4169 alloy sheet after cold rolling (at 0\%, 10\%, 30\%, 50\% and $70 \%$ ) and solid solution were investigated. The textures and Taylor factors were characterized using electron backscattering diffraction (EBSD). The fractions of $\delta$ phase were measured by X-ray diffraction. The contributions of $\delta$ phase, grain size, texture, and work hardening on the mechanical properties were also discussed. The results showed increases in the yield strength (YS) $(0.2 \%)$ as well as the ultimate tensile strength (UTS) of GH4169 superalloy sheet after cold rolling, when rolling reduction was increased. In contrast, following solid solution treatment, YS and UTS were increased then subsequently decreased. The changes of yield strength of GH4169 superalloy were attributed to the texture and work hardening, followed by the grain refinement and precipitation of $\delta$ phase. When the rolling reduction was below $30 \%$, the influence of $\delta$ phase was greater than grain refinement and when the rolling reduction was larger than $50 \%$, the controversial results occur. The precipitation of $\delta$ phase promoted the improvement of yield strength, the relationship between the fraction of $\delta$ phase and improved yield strength satisfactory fit to the following equation: $\sigma_{\delta}=15.9 W_{\delta}+59.7$.
\end{abstract}

Keywords: GH4169 alloy; cold rolling; mechanical property; phase fraction; heat treatment

\section{Introduction}

GH4169 alloy is a nickel base superalloy (modified IN718) strengthened by the precipitation of ordered body centered cubic (BCC) $\gamma^{\prime \prime}-\mathrm{Ni}_{3} \mathrm{Nb}$ and ordered face centered cubic (FCC) $\gamma^{\prime}-\mathrm{Ni}_{3}(\mathrm{Al}$, Ti) [1,2]. It is extensively used in aerospace, nuclear, and petrochemical industries because of its excellent mechanical properties, good oxidation resistance, and corrosion at elevated temperature. The strengthened phase of $\gamma^{\prime \prime}$ is metastable [3-6], which can be transformed to the orthogonal thermodynamic equilibrium $\delta-\mathrm{Ni}_{3} \mathrm{Nb}$ phase below $900{ }^{\circ} \mathrm{C}$. However, when the temperature is $>900{ }^{\circ} \mathrm{C}$, the $\delta$ phase can also be precipitated directly from the matrix [7]. The $\delta$ phase existed in the GH4169 alloy plays important effects on the creep properties and microstructure's evolution [8,9]. It reduces the notch sensibility and controls the grain growth through precipitation on the grain boundaries [10-12]. The effect of $\delta$ phase on the hot deformation behavior and plasticity of GH4169 superalloy has been widely analyzed. The existence of $\delta$ phase results in the decreasing of flow stress 
and makes the flow stress reached a peak value at small strain. Besides, the $\delta$ phase increases the strain rate sensitivity exponent, it decreases the strain hardening exponent [13]. Zhang [14] discussed the initial $\delta$ phase on the hot tensile deformation behavior of a Ni-based superalloy. The results showed that $\delta$ phase causes obvious work hardening at the beginning of hot deformation and accelerates flow softening via promoting the dynamic recrystallization with further strain. Therefore, the Delta Process became the most widely used components in aerospace applications. It successfully utilizes the pre-precipitated $\delta$ phase prior hot deformation to obtain fine grains through the pinning effect on the grain boundaries. Recently, cold rolling technology was firstly adopted to form blades, based on the requirements of precise forming and fatigue strength improvement.. Liu et al. [15] analyzed the phases' fraction of cold rolled Inconel 718. They found that the process of cold rolling promoted the precipitation of $\delta$ phase. Although, it increased the $\delta$ phase's fraction, the fraction of $\gamma^{\prime \prime}$ phase was decreased oppositely. So, adjusting the $\delta$ phase's fraction is important to get the best performance of GH4169 alloy at room-temperature [11].

There were some results acquired in previous research, but they were mainly focus on the phases' precipitation after cold deformation, little attention was paid on the mechanical properties of GH4169 alloy after cold deformation or heat treatment. For the blade forming, these two processes were both important to the final properties of blades. Especially the period of annealing at $980{ }^{\circ} \mathrm{C}$, it not only determined the phase content, but also has a significant effect on the grain refinement $[8,10,11]$. Besides, the texture and its effect on the mechanical property of alloy were also needed to be paid attentions $[15,16]$. The final mechanical properties of GH4169 alloy would be affected by the factors mentioned above. Moreover, to understand how much they would provide a theoretical guidance for further process optimization of cold rolling technology. So, the grain size, texture, phase fraction after cold rolling and heat treatment and their effects on the mechanical properties of GH4169 alloy at room temperature were needed to be analyzed.

\section{Experimental Procedures}

The cold rolled GH4169 superalloy sheet with the size of $70 \times 21 \times 2.5 \mathrm{~mm}$ was used in this paper. It was annealed at $990{ }^{\circ} \mathrm{C} / 1 \mathrm{~h}$. The chemical compositions include: $\mathrm{Ni}$ 52.90, Cr 17.96,Mo 3.04, $\mathrm{Nb} 5.00, \mathrm{Al}$ 0.51, Ti 1.02, C 0.042, P 0.005, S 0.003,Si 0.17 (wt. \%), and Fe Bal. OM micrograph is shown in Figure 1.The annealing sheets were firstly cold rolled to different reductions in thickness, i.e., $0 \%, 10 \%, 30 \%, 50 \%$ and $70 \%$ (named cold rolled specimen, CRS), then solid solution treated at $980{ }^{\circ} \mathrm{C} / 1 \mathrm{~h}$ (named solid solutioned specimen, SSS). The tensile tests were carried on the MTS E45 (MTS, Eden Prairie, MN, USA) at the velocity of $1 \mathrm{~mm} / \mathrm{min}$ to acquire the $0.2 \%$ yield strength (YS) and ultimate tensile strength (UTS). The microstructures were observed on Zeiss Observation Z1m optical microscope (Carl Zeiss AG, Baden, German). The Electron Backscattered Diffraction (EBSD) data were acquired on the Hitachi S3400N scanning electron microscope (Hitachi Ltd, Tokyo, Japan) with Oxford Instrument HKL system (Oxford Instruments, Oxfordshire, UK). The scan step was $1 \mu \mathrm{m}$ and the voltage was $20 \mathrm{kV}$. Phases of the alloy with different cold rolling reductions were measured by RigakuD/max- $\gamma$ A diffractometer (Hitachi Ltd, Tokyo, Japan) and the weight percentages of $\delta$ phase were calculated according to Liu et al., methodology [17] which the error can be controlled within 10\% [18-20]. Additionally, other annealing experiments were carried out to obtain the values of $K$ and $\sigma_{0}$ in the Hall-Petch relationship. They were heated rapidly at $100{ }^{\circ} \mathrm{C}$ and $1040{ }^{\circ} \mathrm{C}$ for $1 \mathrm{~h}$ separately to avoid the influence of $\delta$ phase. 


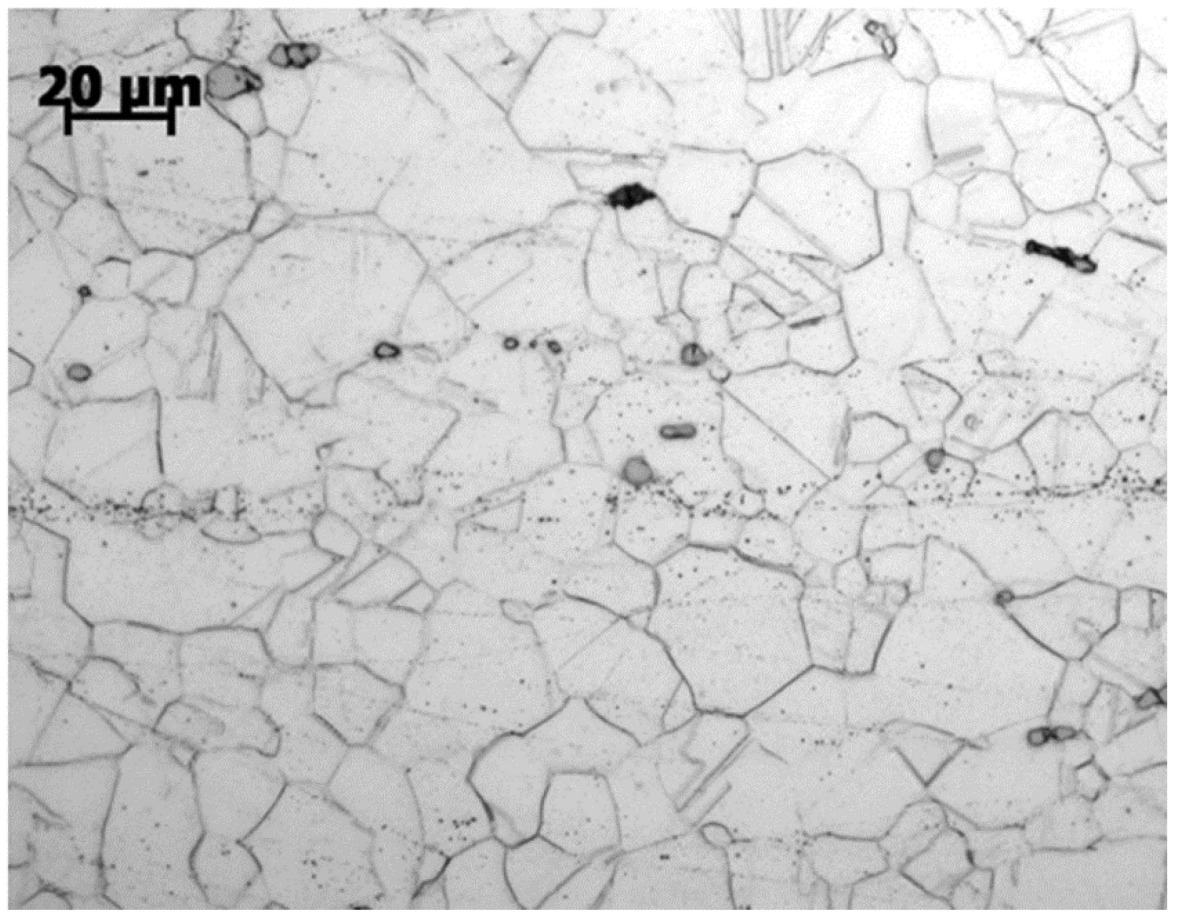

Figure 1. Microstructure of GH4169 alloy after annealing $\left(990^{\circ} \mathrm{C} / 1 \mathrm{~h}\right)$.

\section{Results and Discussion}

\subsection{Microstructure Evolution}

The microstructure evolution of cold rolling and solid solution are shown in Figure 2. As can be seen, the increases of rolling reduction elongate the grains along the rolling direction. Meanwhile, plenty of deformation bands were formed, as shown in Figure 2a,b. After solid solution, $\delta$ phase gradually precipitated and its morphology transformed from needle-shaped to particle-shaped. The morphology of $\delta$ phase (when the rolling reduction $=30 \%$ ) was needle-shaped and preferentially precipitated on the grain and twin boundaries. $\delta$ phase was also precipitated on the deformation bands and it was relative to small content, as shown with the black arrows in Figure 2c. On the other hand, when the rolling reduction reached $50 \%$, the morphology of $\delta$ phase was mainly particle-shaped and largely precipitated both on the boundaries and deformation bands of grains, as shown with the black arrows in Figure 2d. Clearly, it reveals that large rolling reduction not only promotes the precipitation of $\delta$ phase, but also leads to the transformation of its morphology. However, distinguishing from the one formed in the hot deformation or heat treatment temperature below $900{ }^{\circ} \mathrm{C}$, Notably, the particle-shaped $\delta$ phase in this paper neither originated from the phase transformation of $\gamma^{\prime \prime} \rightarrow \delta$ nor spheroidized by deformation breakage or dissolution breakage. Obviously, it is related to the deformation bands and vacancies formed in the cold rolling process and the static recrystallization occurred in the heat treatment. When the rolling reduction reached $50 \%$, static recrystallization was occurred at $980{ }^{\circ} \mathrm{C}$ which can be seen in later analysis. It weakens the orientation relationship between $\delta$ phase and matrix. Besides, high-angle grain boundaries were increased due to static recrystallization. It reveals that the deformation energy is high on these grain boundaries, which can result in the $\delta$ phase preferentially precipitated with a high energy (but not stable state), i.e., particle-shaped. 


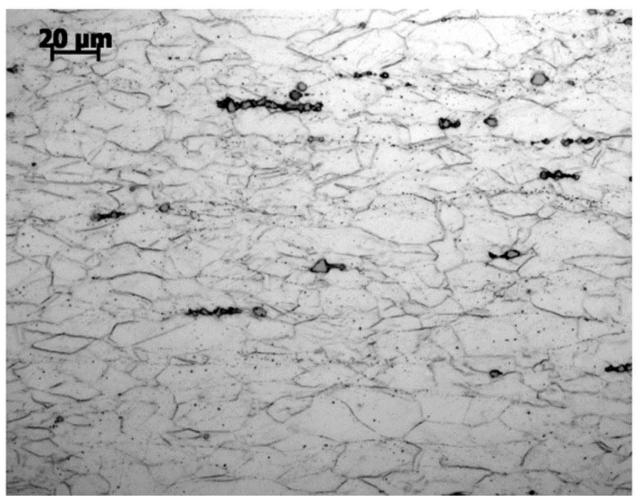

(a)

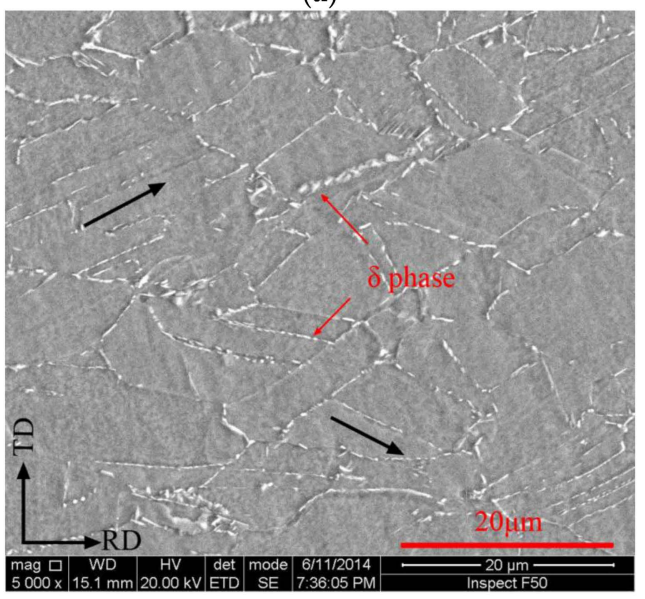

(c)

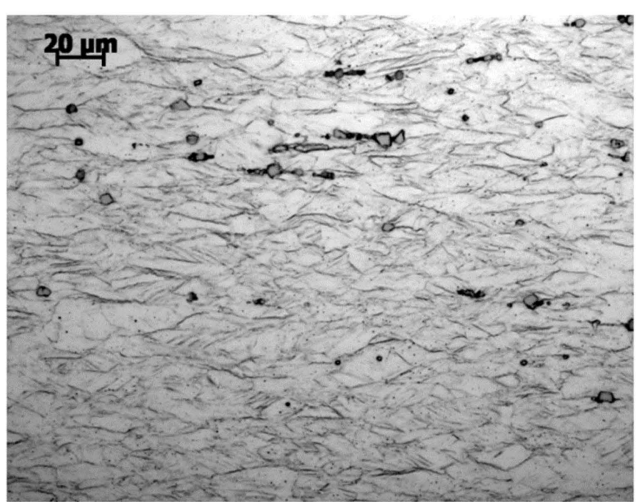

(b)

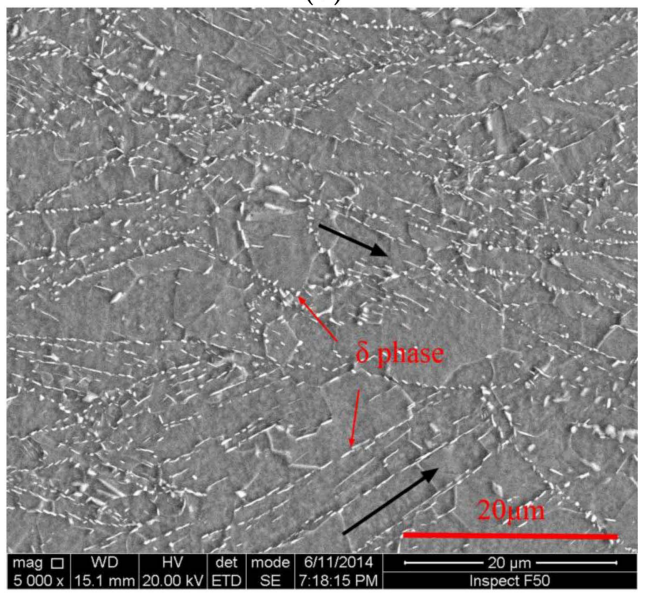

(d)

Figure 2. Microstructure evolution under different rolling reductions (980 ${ }^{\circ} \mathrm{C} 1 \mathrm{~h}$ ) (a) $\varepsilon=30 \%$ (b) $\varepsilon=50 \%$ after cold rolling (c) $\varepsilon=30 \%$ (d) $\varepsilon=50 \%$ after solid solution.

\subsection{Phase Fraction}

Figure 3 demonstrates the diffraction patterns and phase fractions (wt. \%) of SSS with different rolling reductions. It shows that the diffraction peaks of $\delta$ phase were gradually developed with the increases of rolling reduction, as shown with the arrow in Figure 3a. With the rolling reduction increasing from $0 \%$ to $30 \%$, fraction of $\delta$ phase increases from $1.82 \%$ to $3.52 \%$. When the rolling reduction reached to $70 \%$, the fraction increased to $6.93 \%$. The increase of $\delta$ phase's fraction was due to the large deformation during cold rolling process. In the process of cold rolling, the super vacancies were firstly formed with dislocations. However, in the heat treatment, $\mathrm{Nb}$ atoms were easily attracted by the super vacancy and finally form the vacancy- $\mathrm{Nb}$ atom pairs. Subsequently, the vacancy- $\mathrm{Nb}$ atom pairs diffuse to the defect rich on the deformation bands. It provides the necessary condition for the mass nucleation of $\delta$ phase, because of $\mathrm{Nb}$ element's non-equilibrium segregation. So the fraction of $\delta$ phase was increased with the rolling reduction after heat treatment. 


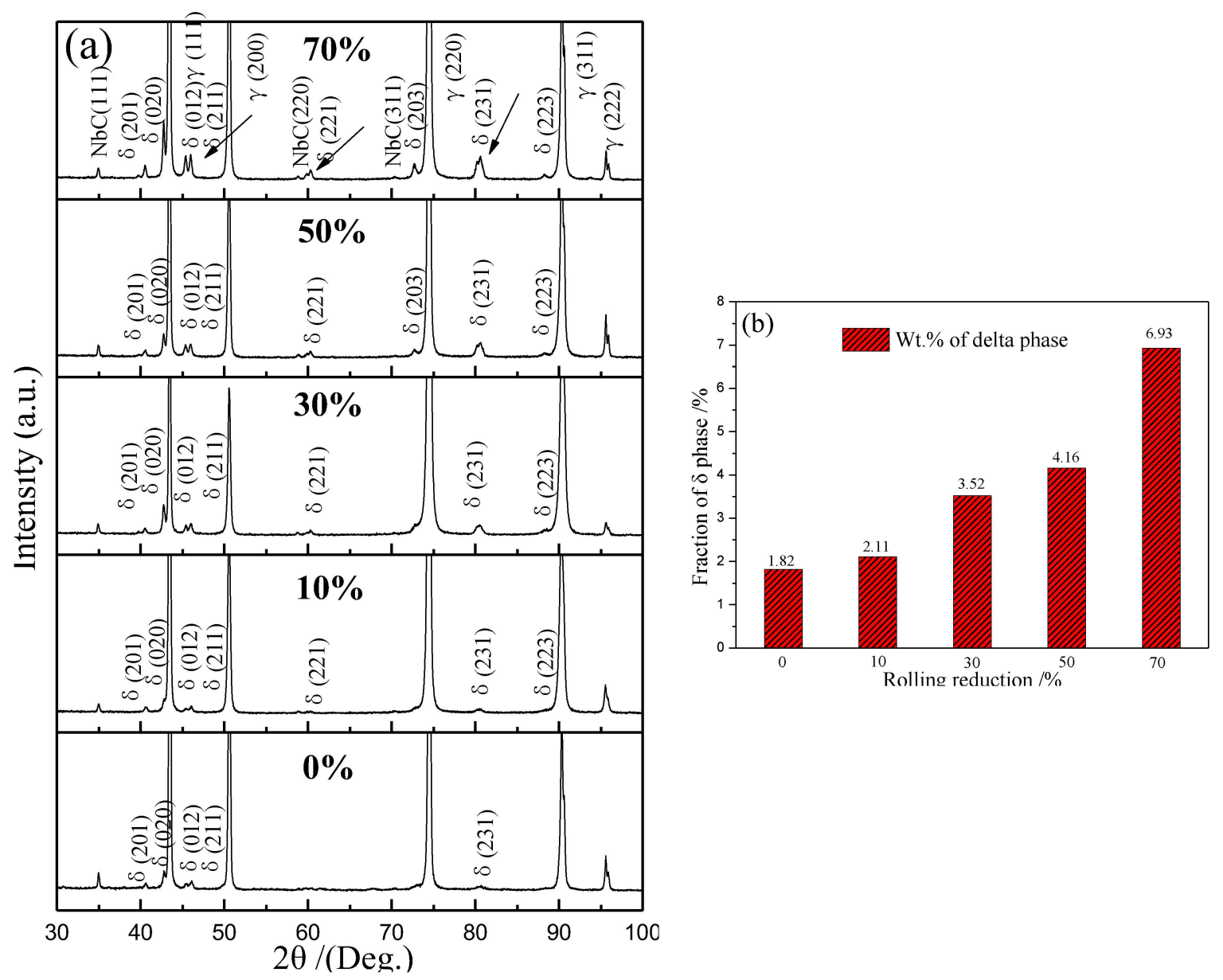

Figure 3. Diffraction patterns and phase fractions after solid solution under different cold rolling reduction (a) Diffraction patterns (b) Phase fractions.

\subsection{Mechanical Properties}

The mechanical properties will are changed due to the microstructure evolution and phase precipitation. The YS and UTS of CRS and SSS are shown in Figure 4. From Figure 4a,b, it can be seen that the YS and UTS of CRS increase with the increase of rolling reduction. On the contrary, the YS and UTS of SSS firstly increased then slightly decreased, when the rolling reductions increased. The YS and UTS of un-deformed CRS $(0 \%)$ were 379.4 and $858.5 \mathrm{MPa}$, respectively. After cold rolling, the YS and UTS increased by 195.2 and $183.2 \mathrm{MPa}$, when the rolling reduction increases from $0 \%$ to $30 \%$, respectively. When the rolling reduction reaches 70\%, they further increases by 156.3 and 219.6 MPa separately comparing to the rolling reduction of 30\%. After solid solution, the YS and UTS of un-deformed SSS0\% were 457.3 and $923.2 \mathrm{MPa}$, respectively. They increased by 77.9 and $64.7 \mathrm{MPa}$ compared to un-deformed CRS, as shown with the arrow in Figure 4. With increasing the rolling reduction to $30 \%$, the YS and UTS of SSS increased to 624.1 and $1136.1 \mathrm{MPa}$; and $166.8 \mathrm{MPa}$ and 212.9 $\mathrm{MPa}$, respectively. However, when the rolling reduction reaches to $70 \%$, the YS and UTS decreased to 593.6 and $1111.3 \mathrm{MPa}$, and $30.5 \mathrm{MPa}$ and $24.8 \mathrm{MPa}$, respectively. These variations are relative to phase precipitation, static recrystallizaiton, texture and work hardening. 

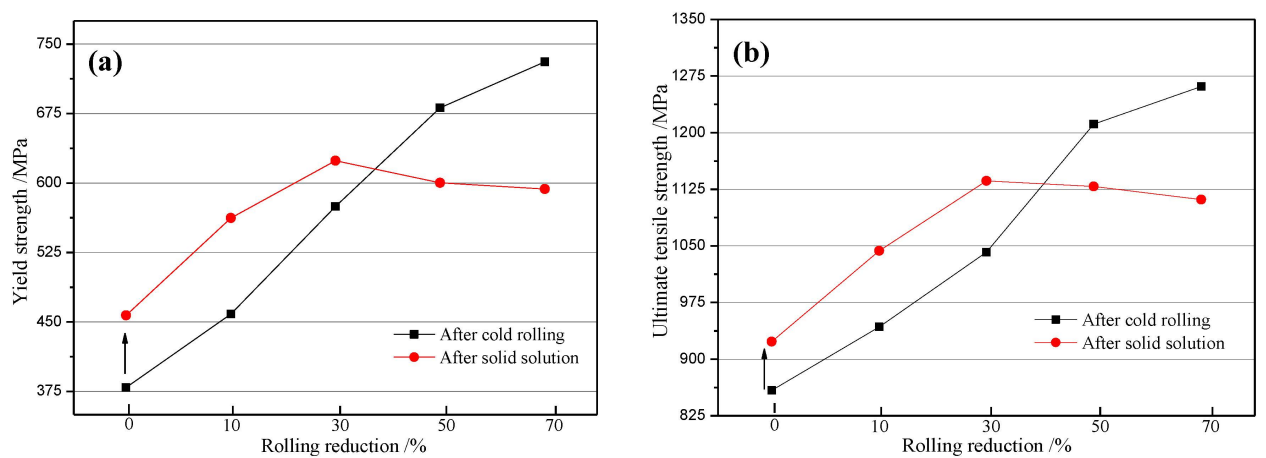

Figure 4. Mechanical properties after cold rolling and solid solution (a) Yield strength (b) Ultimate tensile strength.

\subsection{Discussion}

\subsubsection{Strength Variation after Cold Rolling}

In the process of cold rolling, the movement and tangle of dislocations formed a lot of deformation bands and sub-grain structure, as shown with black arrows in Figure 5a,b. The texture of $\{110\}<112>C$ type was formed simultaneously, as shown in Figure 5d,e. When reduction ratio reached to $50 \%$, the sub-grain structure and the texture were slightly reduced and weakened respectively as shown in Figure 5c,f.

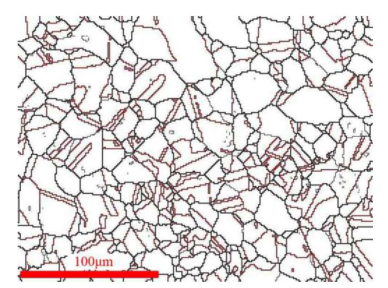

(a)

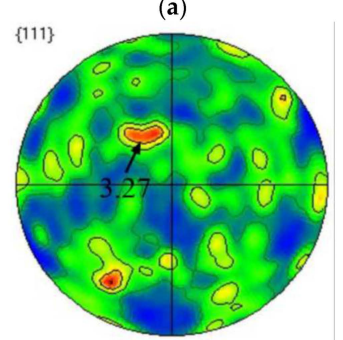

(d)

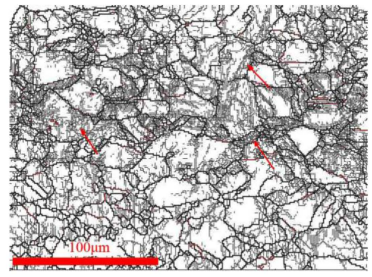

(b)

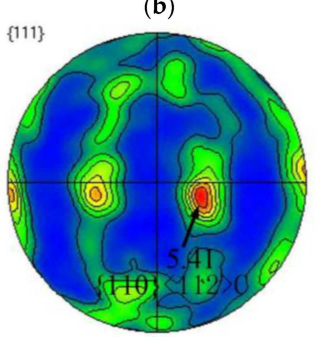

(e)

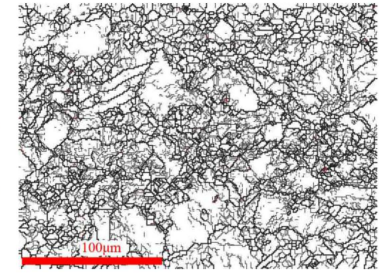

(c)

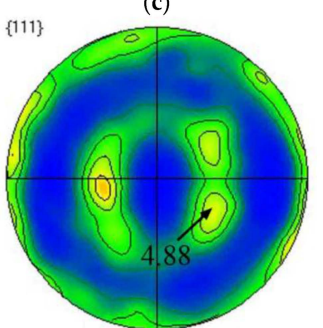

(f)

Figure 5. Microstructure and pole maps under different cold rolling reduction $(\mathbf{a}) /(\mathbf{d}) \varepsilon=0 \%$ (b) $/(\mathbf{e}) \varepsilon=30 \%(\mathbf{c}) /(\mathbf{f}) \varepsilon=50 \%$.

From Figure $5 \mathrm{a}-\mathrm{c}$, it can be seen that the grain size were changed with the increases of rolling reduction. From $0 \%$ to $30 \%$, the grain size decreases from 11.9 to $11.7 \mu \mathrm{m}$. Further decline $(9.8 \mu \mathrm{m})$ was recorded, when the rolling reduction increases to $50 \%$.

To get the values of $K$ and $\sigma_{0}$ in Hall-Petch relationship, size of 33.8 and $82.5 \mu \mathrm{m}$ grains were acquired by annealing to the original sheet at $1000{ }^{\circ} \mathrm{C}$ and $1040{ }^{\circ} \mathrm{C}$ for $1 \mathrm{~h}$, separately. Their corresponding YS were 347.6 and $313.84 \mathrm{MPa}$, separately. By linear fitting, the values of $K$ and $\sigma_{0}$ were $547.1 \mathrm{MPa} \cdot \mathrm{mm}^{1 / 2}$ and $253.6 \mathrm{MPa}$, respectively. In turn, the Hall-Petch relationship based on the GH4169 superalloy can be expressed:

$$
\sigma_{\mathrm{d}}=253.6+547.1 d^{-1 / 2}
$$


where $\sigma_{\mathrm{d}}$ is the $Y \mathrm{~S}^{\prime}$ variable value due to grain size, $d$ is the average grain size. According to Equation (1), it can be implied that the grain size after cold rolling just has a small effect on the YS after cold rolling. Therefore, it is neglected in this part.

Except the grain sizes, the textures are also changed, as shown in Figure 5d-f. Taylor factor is a function of grain orientation and applied stress field. Therefore, the effect of texture evolution on the YS of CRS can be expressed [16]:

$$
\Delta \sigma_{\mathrm{T}}=M_{i} \tau_{i}-M_{j} \tau_{j}
$$

where $\Delta \sigma_{\mathrm{T}}$ is the YS' variable value due to texture evolution, $M_{i}, M_{j}$ are the average values of Taylor factor under different rolling reductions, $\tau_{i}, \tau_{j}$ are critical shear stress which can be calculated:

$$
\tau=\tau_{0}+\alpha G b \rho^{1 / 2}
$$

where $\tau_{0}$ is the stress necessary to move a dislocation in the absence of other dislocations. It is also neglected due to its small value [21]. $\alpha=0.5$ is a constant value between 0.3 and 0.6 [21]. $G=76.3 \mathrm{GPa}$ is the shear modulus. $b=36.3^{-8} \mathrm{~cm}$ is the Burgers vector. $\rho$ is the dislocation density, which describes the level of work hardening and can be calculated as following [22]:

$$
\rho=\frac{\beta^{2}}{4.35 b^{2}}
$$

where $\beta$ is the full wave at half maximum (FWHM) for diffraction peak at halof GH4169 superalloy. From Equations (2)-(4), it can be seen that Equation (2) describes the coordinate effect of texture and working hardening on the YS.

Figure 6 is the evolution of Taylor factors under different rolling reduction of CRS. It shows that it firstly increases from 3.017 to 3.083, then decreased to 3.018. The Taylor factor under different rolling reductions do not change so much due to its FCC structure.

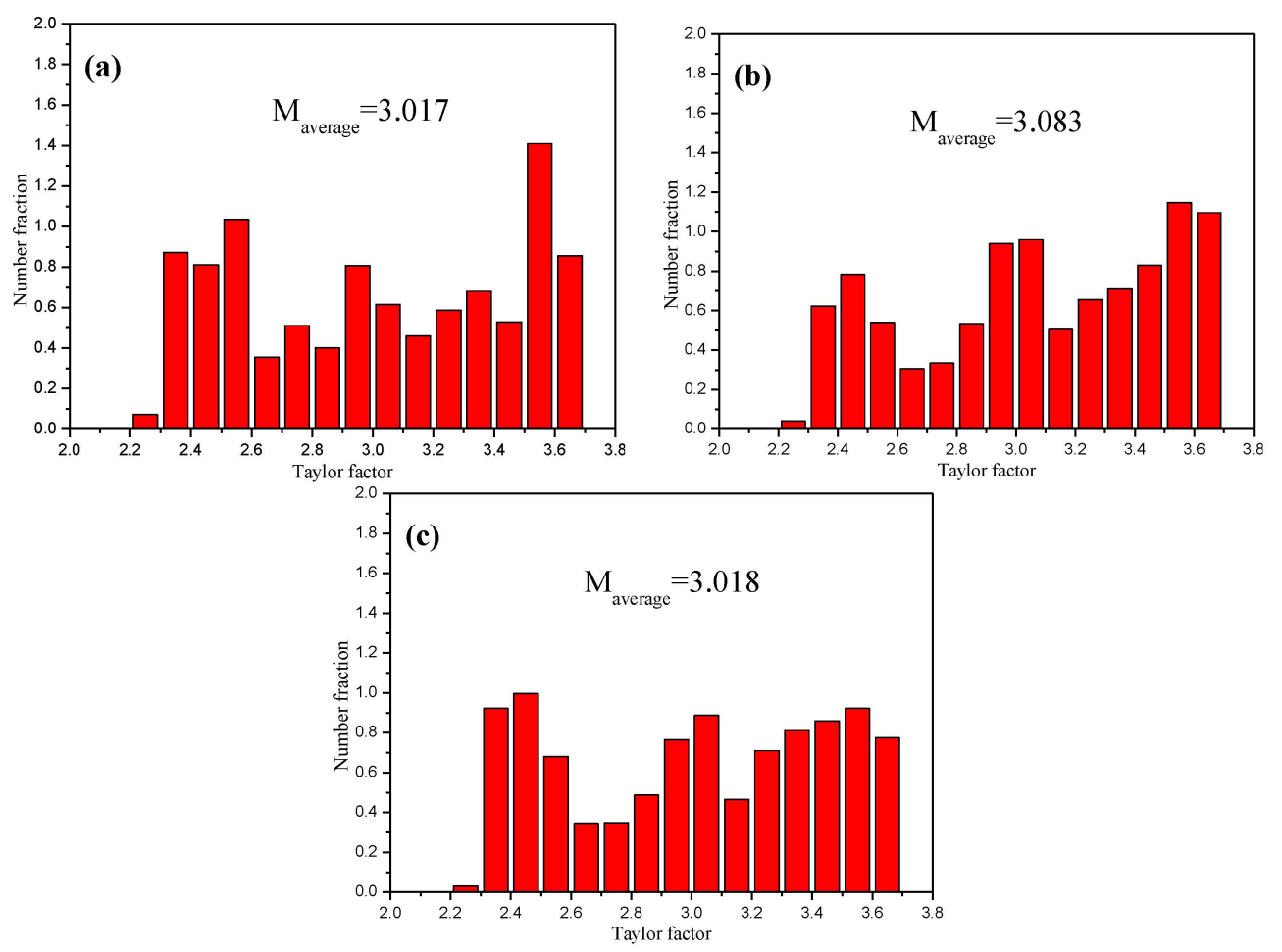

Figure 6. Taylor factor under different rolling reduction. 
According to Equations (2)-(4), the effects of texture and work hardening on the YS of CRS are shown in Table 1 . When cold rolling reduction increases from $0 \%$ to $30 \%$, the contribution of texture and work hardening on the YS was approximately $233.4 \mathrm{MPa}$. When the rolling reduction reaches to $50 \%$, the contribution was further increased by $109.9 \mathrm{MPa}$. It has the same trend with experiment results, as $\Delta \sigma_{\mathrm{c}}$ shown in Table 1.

Table 1. Effects of texture and work hardening on the yield strength (YS) of cold rolled specimen (CRS).

\begin{tabular}{|c|c|c|c|c|c|c|c|c|c|}
\hline \multicolumn{3}{|c|}{$\beta \times 10^{-3} / \mathrm{rad}$} & \multicolumn{3}{|c|}{$\tau_{i} / \mathrm{MPa}$} & \multicolumn{2}{|c|}{$\Delta \sigma_{\mathrm{T}} / \mathrm{Mpa}$} & \multicolumn{2}{|c|}{$\Delta \sigma_{\mathrm{c}} / \mathrm{Mpa}$} \\
\hline $0 \%$ & $30 \%$ & $50 \%$ & $0 \%$ & $30 \%$ & $50^{\circ}$ & $0 \% \rightarrow 30 \%$ & $30 \%$ & $\% \rightarrow 30 \%$ & $30 \%$ \\
\hline 7.1 & 11.1 & 13.3 & 130.1 & 203.0 & 243.8 & 233.4 & 109.9 & 195.2 & 155.5 \\
\hline
\end{tabular}

Although the Taylor factors did not change so much during cold rolling process, the texture does have a great influence on the YS of CRS with the help of work hardening, including deformation bands and sub-grain structures.

\subsubsection{Strength Variation after Solid Solution}

After solid solution, $\delta$ was precipitated, except grain and texture's evolutions, which can be seen from Figures 2 and 3.

When the rolling reduction was below $30 \%$, the dislocation density was obviously reduced, due to static recovery during solid solution and the appeared annealing twins (red lines in Figure 7a,b. In turn, the influence of work hardening was weakened, however, the texture of $\{110\}<112>C$ type was reserved (Figure 7d,e). The maximum values of pole density are nearly the same as the situation of CRS. However, when the rolling reduction reached 50\%, static recrystallization occurs, as shown in Figure 7c. Not only, it leads to the decreases of dislocation density and grain size, but also decreases the maximum values of pole density from 4.88 to 2.70 (Figure $7 \mathrm{f}$ ).

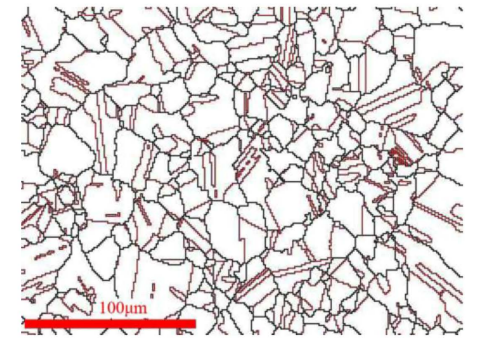

(a)

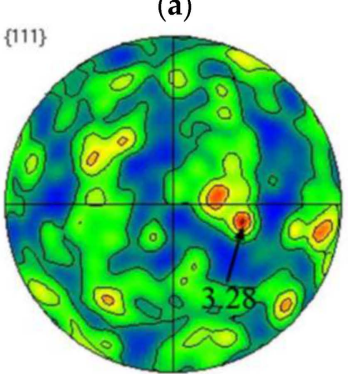

(d)

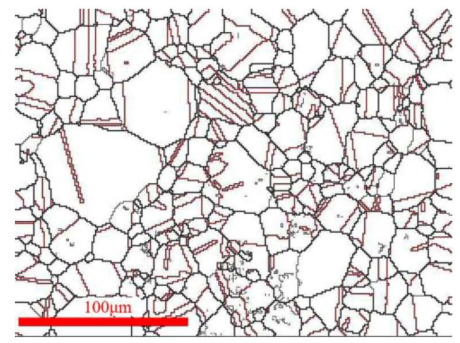

(b)

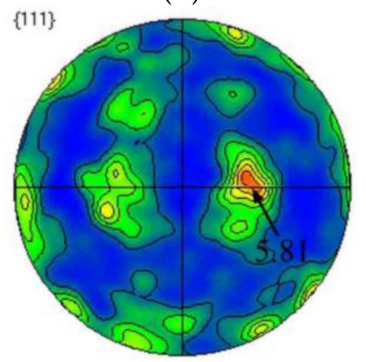

(e)

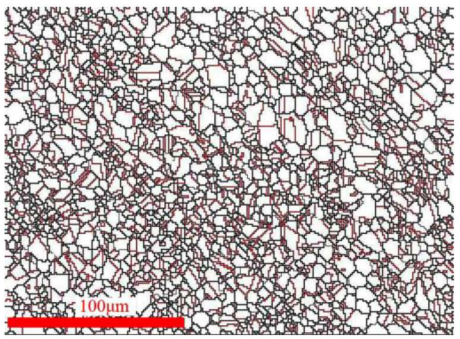

(c)

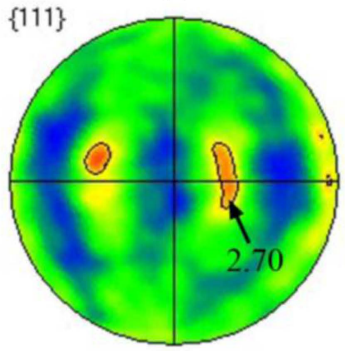

(f)

Figure 7. Microstructure and pole maps under different cold rolling reduction $(\mathbf{a}) /(\mathbf{d}) \varepsilon=0 \%$ (b) $/(\mathbf{e}) \varepsilon=30 \%(\mathbf{c}) /(\mathbf{f}) \varepsilon=50 \%$.

After solid solution, the grain size of SSS with rolling reduction $0 \%, 30 \%$, and $50 \%$ were $11.6,11.5$ and $5.1 \mu \mathrm{m}$ respectively. For the situation of rolling reduction under 0 and $30 \%$, the effect of grain 
size on the YS of SSS was ignored because of small differences. However, when the rolling reduction reached $50 \%$, the grains were refined a lot due to static recrystallization. The contribution of grain size on the YS of SSS reach $81.4 \mathrm{MPa}$ compared to rolling reduction under 30\%. There might be a critical rolling reduction for static recrystallizaiton of cold rolled GH4169 superalloy sheet; the assumption that needs further research works.

During the solid solution, the texutre was also changed due to static recrystallizaiton. The evolution of Taylor factor under different rolling reduction of SSS was shown in Figure 8. The Taylor factor was firstly increased from 2.877 to 3.012 then it decreased to 2.924 .

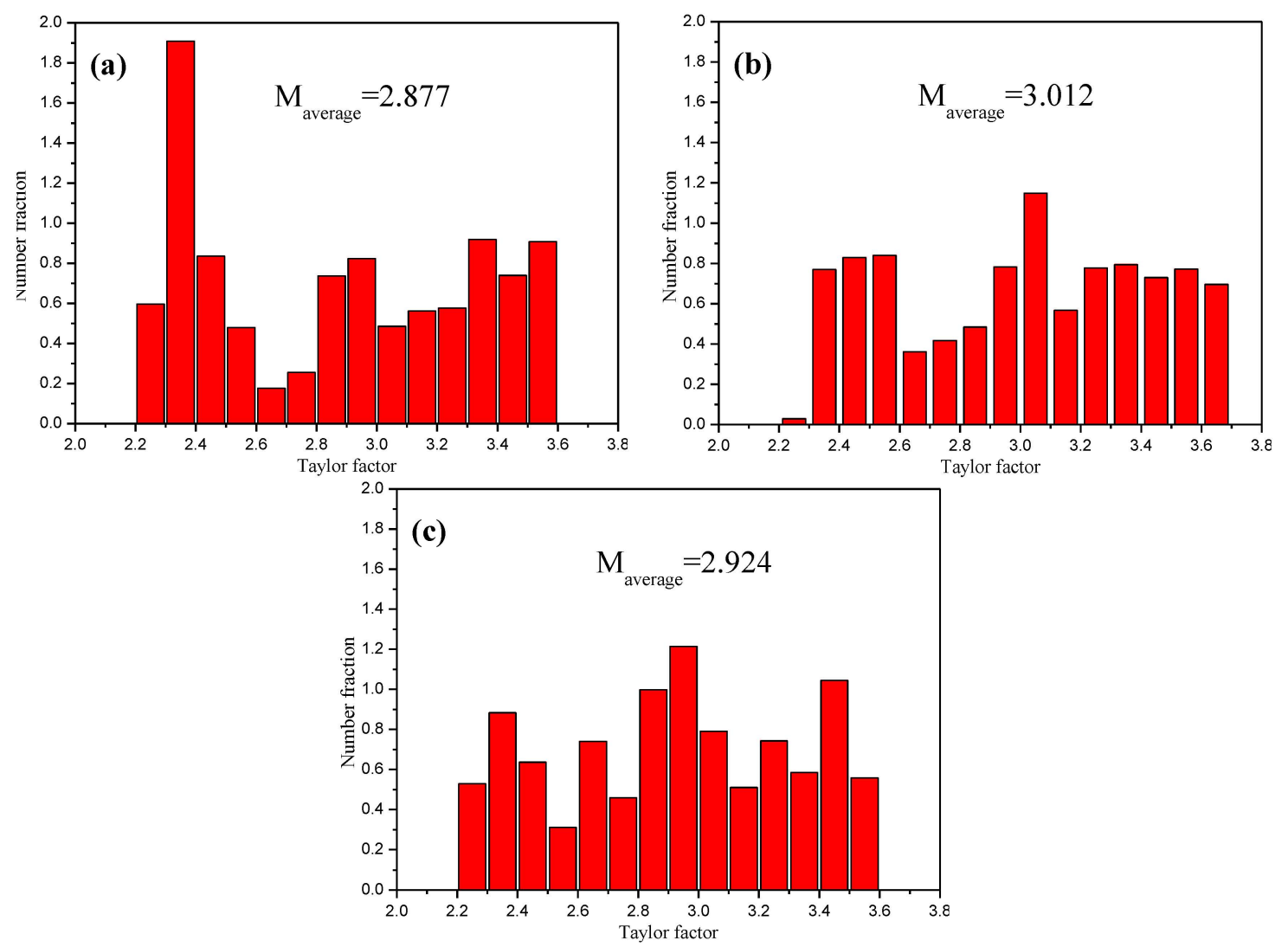

Figure 8. Taylor factors after solid solution (a) $\varepsilon=0 \%$ (b) $\varepsilon=30 \%$ (c) $\varepsilon=70 \%$.

According to Equations (2)-(4), the effects of texture and work hardening after solid solution on the YS are shown in Table 2. When rolling reduction increased from $0 \%$ to $30 \%$, the contribution of texture and work hardening on the YS was approximately $146.2 \mathrm{MPa}$; whereas, the contribution decreased by $131.4 \mathrm{MPa}$, when the rolling reduction reaches to $50 \%$. Even though, we might consider the improvement of grain refinement on the YS, there is still a big difference between the calculated and experimental values, as $\Delta \sigma_{\mathrm{c}}$ shown in Table 2. It might be considered that $\mathrm{c}$ the precipitation of $\delta$ phase has an effect on the YS of SSS.

Table 2. Effects of texture and work hardening on the YS of solid solutioned specimen (SSS).

\begin{tabular}{cccccccccc}
\hline \multicolumn{2}{c}{$\boldsymbol{\beta} \times \mathbf{1 0}^{-\mathbf{3}} / \mathbf{r a d}$} & \multicolumn{3}{c}{$\boldsymbol{\tau}_{\boldsymbol{i}} / \mathbf{M P a}$} & \multicolumn{2}{c}{$\boldsymbol{\Delta \boldsymbol { \sigma } _ { \mathrm { T } } / \mathbf { M P a }}$} & \multicolumn{2}{c}{$\boldsymbol{\Delta \boldsymbol { \sigma } _ { \mathrm { c } } / \mathbf { M P a }}$} \\
\hline $0 \%$ & $30 \%$ & $50 \%$ & $0 \%$ & $30 \%$ & $50 \%$ & $0 \% \rightarrow 30 \%$ & $30 \% \rightarrow 50 \%$ & $0 \% \rightarrow 30 \%$ & $30 \% \rightarrow 50 \%$ \\
7.3 & 9.7 & 7.5 & 134.3 & 176.8 & 137.2 & 146.2 & -131.4 & 166.8 & -30.5 \\
\hline
\end{tabular}

In Figures $3 \mathrm{~b}$ and $4 \mathrm{a}$, there was $1.82 \%$ (wt. \%) of $\delta$ phase precipitated from un-deformed specimen during solid solution. Meanwhile, the corresponding YS was increased by 77.9 MPa. 
Considering the fraction of phase and the changes of YS [23], there is a liner relationship between the fraction of $\delta$ phase and yield strength's improvement, expressed as

$$
\sigma_{\delta}=15.9 \mathrm{~W}_{\delta}+59.7
$$

where $\sigma_{\delta}$ is the contribution of $\delta$ phase to yield strength's improvement of GH4169 superalloy, $W_{\delta}$ is the fraction (wt. \%) of $\delta$ phase.

According to Equation (5), when the fraction of $\delta$ phase increased from $1.82 \%$ to $3.5 \%$, the contribution of $\delta$ phase on the YS of SSS increased from 88.6 MPa to $115.7 \mathrm{MPa}$, and $27.1 \mathrm{MPa}$, respectively. When the rolling reduction reaches to $50 \%$ and the fraction of $\delta$ phase increases to $6.93 \%$, the contribution was also increased to $169.9 \mathrm{MPa}$. It increases by $54.2 \mathrm{MPa}$ compared to $30 \%$ rolling reduction is $30 \%$; however, YS still reveals a decreasing trend. When the rolling reduction reaches $<50 \%$, the texture and work hardening were completely disappeared, due to static recrystallization. It leads to YS decrease by $131.4 \mathrm{MPa}$ according to Equations (2)-(4), as shown in Table 2. Besides, according to Ref. [1], it shows that when the second phase precipitated from the matrix, the contribution of solid solution strengthening decreased approximately to $20 \mathrm{MPa}$ due to consumption of the strengthening elements. Therefore, considering the influence of $\delta$ phase's precipitation on the solid solution strengthening, the reason of the decreasing yield strength when the rolling reduction is larger than $50 \%$ are grain refinement, precipitation of $\delta$ phase, disappear of texture and work hardening. Moreover, the influence degrees are in the following order: texture and work hardening $>$ grain refinement $>$ precipitation of $\delta$ phase.

\section{Conclusions}

(1) Following the increase of cold rolling reduction, the yield strength and ultimate tensile strength of GH4169 superalloy sheet were substantially increased, however, they were increased then decreased following solid solution.

(2) The main reasons for yield strength changes of GH4169 superalloy are texture and work hardening, followed by the grain refinement and precipitation of $\delta$ phase. When the rolling reduction was below $30 \%$, the influence of $\delta$ phase was greater than grain refinement and the opposite happen when the rolling reduction was larger than $50 \%$.

(3) The precipitation of $\delta$ phase promotes the improvement of yield strength and the relationship between the fraction of $\delta$ phase and the improvement of yield strength satisfies the following equation: $\sigma_{\delta}=15.9 \mathrm{~W}_{\delta}+59.7$.

Acknowledgments: This work was supported by the fund of Special Inventive Fund of Science and Technology in Shenyang under the Contract Number F15-172-6-00 and the State Key Laboratory of Advanced Processing and Recycling of Non-ferrous Metals, Lanzhou University of Technology under the Contract Number SKLAB02014001.

Author Contributions: During the writing of this paper, we benefited from suggestions and critical insights provided by S.H.Z., M.C. and H.W.S. Valuable comments on a first draft were received from H.W.Z. and P.B.W. All experiments and analysis in this paper were accomplished by N.Y.Y.

Conflicts of Interest: The authors declare no conflict of interest.

\section{References}

1. Ahmadi, M.R.; Povoden-Karadeniz, E.; Whitmore, L.; Stockinger, M.; Falahati, A.; Kozeschnik, E. Yield strength prediction in Ni-base alloy 718Plus based on thermo-kinetic precipitation simulation. Mater. Sci. Eng. A 2014, 608, 114-122. [CrossRef]

2. Fisk, M.; Ion, J.C.; Lindgren, L.E. Flow stress model for IN718 accounting for evolution of strengthening precipitates during thermal treatment. Comput. Mater. Sci. 2014, 82, 531-539. [CrossRef] 
3. Zheng, L.; Zhang, M.C.; Chellali, R.; Bouchikhaoui, H.; Dong, J.X. Oxidation property of powder metallurgy EP741NP Ni-based superalloy at elevated temperatures. Mater. Technol. Adv. Perform. Mater. 2013, 28, 2-128. [CrossRef]

4. Lin, Y.C.; Chen, X.M.; Wen, D.X.; Chen, M.S. A physically-based constitutive model for a typical nickel-based superalloy. Comput. Mater. Sci. 2014, 83, 282-289. [CrossRef]

5. Zheng, L.; Zhang, M.C.; Chellali, R.; Dong, J.X. Investigations on the growing, cracking and spalling of oxides scales of powder metallurgy Rene 95 nickel-based superalloy. Appl. Surf. Sci. 2011, 257, 9762-9767. [CrossRef]

6. Zheng, L.; Zhang, M.C.; Chellali, R.; Dong, J.X. Hot corrosion behavior of powder metallurgy Rene 95 nickel-based superalloy in molten $\mathrm{NaCl}-\mathrm{Na}_{2} \mathrm{SO}_{4}$ salts. Mater. Des. 2011, 32, 1981-1986. [CrossRef]

7. Sundararaman, M.; Mukhopadhay, P.; Banerjee, S. Precipitation of the $\delta-\mathrm{Ni}_{3} \mathrm{~N}_{\mathrm{b}}$ phase in two Ni base superalloys. Metall. Mater. Trans. A 1992, 23, 2015-2028. [CrossRef]

8. Li, H.Y.; Kong, Y.H.; Chen, G.S.; Xie, L.X.; Zhu, S.G.; Sheng, X. Effect of different processing technologies and heat treatments on the microstructure and creep behavior of GH4169 superalloy. Mater. Sci. Eng. A 2013, 582, 368-373. [CrossRef]

9. Yeh, A.C.; Lu, K.W.; Kuo, C.M.; Bor, H.Y.; Wei, C.N. Effect of serrated grain boundaries on the creep property of Inconel 718 Superalloy. Mater. Sci. Eng. A 2011, 530, 525-529. [CrossRef]

10. Kong, Y.H.; Liu, R.Y.; Chen, G.S.; Xie, L.X.; Zhu, S.G. Effects of different heat treatments on the microstructures and creep properties of GH4169 superalloy. J. Mater. Eng. Perform. 2013, 22, 1371-1377. [CrossRef]

11. Du, J.H.; Lv, X.D.; Deng, Q. Effect of heat treatment on microstructure and mechanical properties of GH4169 superalloy. Rare Metal Mater. Eng. 2014, 43, 1830-1834. [CrossRef]

12. Zhou, N.; Lv, D.C.; Zhang, H.L.; McAllister, D.; Zhang, F.; Mills, M.J.; Wang, Y. Computer simulation of phase transformation and plastic deformation in IN718 superalloy: Microstructural evolution during precipitation. Acta Mater. 2014, 65, 270-286. [CrossRef]

13. Wang, K.; Li, M.Q.; Luo, J.; Li, C. Effect of the $\delta$ phase on the deformation behavior in isothermal compression of superalloy GH4169. Mater. Sci. Eng. A 2011, 528, 4723-4731. [CrossRef]

14. Zhang, H.Y.; Zhang, S.H.; Cheng, M.; Li, Z.X. Deformation characteristics of $\delta$ phase in the delta-processed Inconel 718 alloy. Mater. Charact. 2010, 61, 49-53. [CrossRef]

15. Liu, W.C.; Chen, Z.L.; Xiao, F.R.; Yao, M.; Jiang, Z.Q.; Wang, S.G. Effect of cold rolling on the precipitation behavior of $\delta$ phase and $\gamma^{\prime \prime}$ phase in Inconel 718. Acta Aeronaut. Astronaut. Sin. 1999, 20, 279-282. [CrossRef]

16. Hansen, N. Polycrystalline strengthening. Metall. Trans. A 1985, 16A, 2167-2190. [CrossRef]

17. Liu, W.C.; Xiao, F.R.; Yao, M. Quantitative phases analysis of GH4169 by X-ray diffraction. J. Mater. Sci. 1997, 16, 769-771.

18. Liu, W.C.; Xiao, F.R.; Yao, M. Relationship between the lattice constant of $\gamma$ phase and the content of $\delta$ phase, $\gamma^{\prime \prime}$ and $\gamma^{\prime}$ phases in Inconel 718. Scr. Mater. 1997, 37, 59-64. [CrossRef]

19. Li, R.B.; Yao, M.; Liu, W.C.; He, X.C. Isolation and determination for $\delta, \gamma^{\prime \prime}$ and $\gamma^{\prime}$ phases in Inconel 718 alloy. Scr. Mater. 2002, 46, 635-638. [CrossRef]

20. Cai, D.Y.; Liu, W.C.; Li, R.B.; Zhang, W.H.; Yao, M. On the accurancy of the X-ray diffraction quantitative phases analysis method in GH4169. J. Mater. Sci. 2004, 39, 719-721.

21. Rauch, E.F.; Gracio, J.J.; Barlet, F. Work-hardening model for polycrystalline metals under strain reversal at large strain. Acta Meterialia 2007, 55, 2030-2948. [CrossRef]

22. Wang, X.Q.; Cui, F.K.; Yan, G.P.; Li, Y.X. Study on the dislocation density change during cold roll-beating of 40Cr. China Mech. Eng. 2013, 24, 2248-2256.

23. Ye, N.Y.; Cheng, M.; Zhang, S.H.; Song, H.W.; Zhou, H.W.; Wang, P.B. Effect of $\delta$ Phase on Mechanical Properties of GH4169 Alloy at Room Temperature. J. Iron Steel Res. Int. 2015, 22, 752-756. [CrossRef]

(C) 2015 by the authors; licensee MDPI, Basel, Switzerland. This article is an open access article distributed under the terms and conditions of the Creative Commons by Attribution (CC-BY) license (http:/ / creativecommons.org/licenses/by/4.0/). 